\title{
Association among dietary magnesium, serum magnesium, and diabetes: a cross- sectional study in middle-aged and older adults
}

Jie Wei ${ }^{1,2}$, Chao Zeng ${ }^{3}$, Xiao-xiao Li ${ }^{1}$, Qian-yi Gong ${ }^{1}$, Guang-hua Lei ${ }^{3}$ and Tu-bao Yang ${ }^{1 *}$

\begin{abstract}
Background: A number of studies have reported the association between magnesium (Mg) and diabetes. However, the various conclusions were inconsistent and the data on the Chinese population was limited. The objective of this study was to evaluate the association among dietary Mg, serum Mg, and diabetes in Chinese adults.

Methods: A cross-sectional study that contained 2904 subjects was conducted. Biochemical test results and dietary intakes of subjects were collected for analysis. The adjusted odds ratios (ORs) and the corresponding $95 \%$ confidence intervals (95\% Cls) were used to determine the relationship between Mg status and diabetes by logistic regression.

Results: The prevalence of diabetes of the investigated population was $10.1 \%$. Dietary Mg intake was not significantly correlated with diabetes $(P>0.05)$. The significant negative association between serum $\mathrm{Mg}$ and diabetes existed, and the multivariate adjusted OR was $0.34(95 \% \mathrm{Cl} 0.24,0.49)$ in model 3 for the highest quartile of serum $\mathrm{Mg}$ compared with the lowest. The $P$ values for trend were all less than 0.001 for the relationship between serum $\mathrm{Mg}$ and diabetes. Dietary Mg intake and serum Mg were not significantly correlated in the diabetes population $(P=0.936)$.

Conclusions: Dietary Mg was not significantly correlated with diabetes, while serum Mg was inversely correlated with diabetes in the Chinese population. Meanwhile, dietary Mg intake and serum Mg were not significantly correlated in the diabetes population.
\end{abstract}

Keywords: Dietary magnesium, Serum magnesium, Diabetes, Cross-sectional study

\section{Background}

Magnesium (Mg), as the second most major intracellular cation in the human body, is the basic composition of many enzymes and the cofactor in over 300 enzymatic reactions. Thus, it plays a very essential role in energy metabolism, protein and nucleic acid synthesis, transportation of potassium and calcium ions, signal transduction, and cell proliferation [1-3]. $\mathrm{Mg}$ can be found in many foods, especially in whole grains, legumes, green leafy vegetables, and nuts. According to previous researches, $\mathrm{Mg}$ intake may be negatively correlated with several

\footnotetext{
* Correspondence: 1064960669@qq.com

'Department of Epidemiology and Health Statistics, Xiangya School of Public Health, Central South University, Changsha, Hunan Province 410008, China Full list of author information is available at the end of the article
}

chronic diseases, such as metabolic syndrome, diabetes, hypertension, and cardiovascular disease [4-8].

A number of epidemiological and experimental studies have suggested a correlation between $\mathrm{Mg}$ and diabetes, but the conclusions were still inconsistent, especially for the relationship between dietary $\mathrm{Mg}$ and diabetes. Although quite a few studies [9-16] supported the protective role of higher $\mathrm{Mg}$ intake in reducing the risk of diabetes, there were still some studies claiming that the correlation between dietary $\mathrm{Mg}$ and diabetes did not exist [17-23]. Meanwhile, the studies denying such a correlation were mainly reported in Asia [19, 21, 23]. In addition, data on Chinese adults are very limited: only two studies reported the relationship between dietary $\mathrm{Mg}$ intake and diabetes, and both of them were carried out in East China (Shanghai and Jiangsu) [15, 21]. 
Several studies have demonstrated the association between serum $\mathrm{Mg}$ and diabetes in the Chinese population [24-26]. However, no study specifically focused on the relationship among dietary $\mathrm{Mg}$ intake, serum $\mathrm{Mg}$, and diabetes in the Chinese adults.

The objective of this study was to re-evaluate the association between dietary $\mathrm{Mg}$ intake and diabetes in the Chinese adults, to assess the average level of $\mathrm{Mg}$ intake in the central south area of China, and to test the relationship among dietary $\mathrm{Mg}$ intake, serum $\mathrm{Mg}$, and the prevalence of diabetes based on a cross-sectional study with a large sample size.

\section{Methods}

\section{Subjects}

The Xiangya Hospital Health Management Center is one of the largest Health Management Centers in Hunan Province. Participants were recruited while they have their regular health examination. Subjects were selected according to the following inclusion criteria: (1) 40 years old or above; (2) undergoing serum Mg measurement; (3) availability of all basic characteristics, including age, gender, and body mass index (BMI); and (4) completion of a semi-quantitative food frequency questionnaire (SFFQ) about the average consumption of foods and drinks over the past 1 year. This cross-sectional study included 5381 subjects who were undergoing routine checkups including serum $\mathrm{Mg}$ measurement from October 2013 to July 2014. Then, 4830 individuals were over 40 years old and available for the basic characteristics. Eventually, 2904 subjects completed the SFFQ and were included in the present study.

The protocol of our study was approved by the Ethics Committees on Research of the Xiangya Hospital, Central South University.

\section{Dietary assessment}

Dietary intake was evaluated by the SFFQ which was particularly designed for the Chinese population. This SFFQ has been validated and used in several previous published studies [27-29]. It contains 63 food items which are popular and commonly consumed in the Hunan Province of China. For each food item, participants were asked how frequently (never, once a month, two to three times a month, one to three times a week, four to five times a week, once a day, twice a day, or more than twice a day) they consumed the food in the past year. The average amount of food intake for each time was asked with six options: less than $100 \mathrm{~g}, 100-$ $200 \mathrm{~g}, 201-300 \mathrm{~g}, 301-400 \mathrm{~g}, 401-500 \mathrm{~g}$, and more than 500 g. Color pictures of food samples with labeled weights were also given to participants to help them make choices more easily and accurately. The Chinese Food Composition Table [30] was used to calculate the individual composition of macronutrients and micronutrients of the included food items.

\section{Blood biochemical assessment}

All blood samples were drawn after a 12-h overnight fast and were kept at $4{ }^{\circ} \mathrm{C}$ until analysis. Serum $\mathrm{Mg}$, blood fasting glucose, high-density lipoprotein cholesterol (HDL), low-density lipoprotein cholesterol (LDL), and triglyceride (TG) were detected on Beckman Coulter AU 5800 (Beckman Coulter Inc., Brea, CA, USA). Subjects with the blood fasting glucose $\geq 7.0 \mathrm{mmol} / \mathrm{L}$ or currently undergoing drug treatment for blood glucose control were regarded as diabetes patients.

\section{Other covariates assessment}

Blood pressure was measured using an electronic sphygmomanometer. Subjects with the systolic blood pressure $\geq 140 \mathrm{mmHg}$ or diastolic blood pressure $\geq 90 \mathrm{mmHg}$ or currently using antihypertensive medication were regarded as hypertensive patients. The weight and height of each subject were measured to calculate the BMI. Participants were also asked about their average frequency of physical activity (never, one to two times per week, three to four times per week, five times and above per week) and average duration of physical activity (within half an hour, half an hour to $1 \mathrm{~h}, 1$ to $2 \mathrm{~h}$, more than $2 \mathrm{~h}$ ). The educational background and smoking and alcohol drinking status were also asked face to face.

\section{Statistical analysis}

Continuous data was expressed as mean \pm standard deviation, and category data was expressed in percentage. The Mg intake was classified into four categories based on the quartile distribution: $\leq 235.28,235.29-336.06$, 336.07-490.76, and $\geq 490.77 \mathrm{mg} /$ day. Differences in the continuous data were evaluated by the group $t$ test (normally distributed data) or the Mann-Whitney $U$ test (non-normally distributed data). Differences in the category data were assessed by the $\chi^{2}$ test. The odds ratios (ORs) with $95 \%$ confidence intervals (95\% CIs) for the association between $\mathrm{Mg}$ intake and diabetes were calculated for each quartile of $\mathrm{Mg}$ intake, and the lowest quartile was regarded as the reference category. In order to calculate the adjusted $\mathrm{OR}$ for each quartile of $\mathrm{Mg}$ intake, three models were adopted for the multivariate logistic analyses: model 1 included age, sex, BMI $(\geq 5$, $<25 \mathrm{~kg} / \mathrm{m}^{2}$ ), and dietary energy intake of participants; model 2 added dietary fiber, calcium, zinc, and iron intake on the basis of model 1; and model 3 added educational level, activity level, hypertension, alcohol and cigarette using condition, and nutritional supplementation on the basis of model 2. The serum Mg was also classified into four categories based on the quartile distribution: $\leq 0.87,0.88-0.91,0.92-0.96$, and $\geq 0.97 \mathrm{mmol} /$ 
L. Logistic regression was also conducted in three models in order to calculate the adjusted ORs with $95 \%$ CIs for the association between serum $\mathrm{Mg}$ and diabetes: model 1 included age, sex, and BMI $\left(\geq 25,<25 \mathrm{~kg} / \mathrm{m}^{2}\right)$; model 2 added serum triglycerides, serum LDL, and serum HDL on the basis of model 1; and model 3 added educational level, activity level, hypertension, alcohol and cigarette using condition, and nutritional supplementation on the basis of model 2. Tests for linear trends were conducted using the logistic regression with a median variable of $\mathrm{Mg}$ level in each category. The Spearman correlation coefficient was used to detect the relationship between $\mathrm{Mg}$ intake and serum $\mathrm{Mg}$ for the total population, the diabetes population, and the non-diabetes population, respectively.

All data analyses were performed using SPSS 17.0. A $P$ value lower than 0.05 was considered to be statistically significant.

\section{Results}

The basic characteristics of the study population in terms of dietary $\mathrm{Mg}$ intake are shown in Table 1. A total of 2904 subjects aged from 40 to 85 years (1650 males and 1254 females) were included in this cross-sectional study. There was no significant difference between included participants and subjects who were excluded due to incompletion of the SFFQ for age, sex ratio, and BMI. The average level of Mg intake was $378.89 \mathrm{mg} /$ day, which was higher than the dietary reference of $350 \mathrm{mg} /$ day recommended by the Chinese society of nutrition [31]. The average level of serum $\mathrm{Mg}$ was $0.92 \mathrm{mmol} / \mathrm{L}$. There were 294 subjects of confirmed diabetes, and the overall prevalence of diabetes in this research was $10.1 \%$. Age, BMI, smoking rate, dietary energy intake, zinc intake, and serum TG were significantly higher in the diabetes population compared to those in the nondiabetes population. Female rate, serum Mg, and serum HDL of the diabetes population were found to be significantly lower than those of the non-diabetes population. Other characteristics were not significantly different between the two comparing groups.

The results of the multivariable-adjusted relationship between dietary $\mathrm{Mg}$ intake and diabetes are listed in Table 2. After the adjustment by age, sex, BMI, dietary energy intake, fiber intake, calcium intake, zinc intake, iron intake, educational level, activity level, hypertension, alcohol drinking and smoking status, and nutritional supplementation, the ORs and their $95 \%$ CIs did not show a significant correlation between dietary $\mathrm{Mg}$ intake and the prevalence of diabetes. The $P$ values for trend of

Table 1 Characteristics of the study population according to diabetic status

\begin{tabular}{|c|c|c|c|}
\hline & \multicolumn{2}{|l|}{ Diabetic status } & \multirow[t]{2}{*}{ P } \\
\hline & Diabetes population & Non-diabetes population & \\
\hline Age & $53.92 \pm 6.74$ & $52.06 \pm 7.26$ & 0.00 \\
\hline Sex (\% female) & 29.6 & 44.7 & 0.00 \\
\hline BMI $\left(\mathrm{kg} / \mathrm{m}^{2}\right)$ & $26.06 \pm 3.06$ & $24.52 \pm 3.21$ & 0.00 \\
\hline Educational level (\% with or above high school background) & 49.0 & 48.4 & 0.85 \\
\hline Activity level (h/day) & $1.91 \pm 3.22$ & $1.90 \pm 3.19$ & 0.82 \\
\hline Hypertension (\%) & 55.8 & 30.5 & 0.00 \\
\hline Alcohol using (\%) & 39.1 & 37.2 & 0.52 \\
\hline Smoking (\%) & 33.3 & 24.5 & 0.00 \\
\hline Nutritional supplementation (\%) & 29.3 & 33.9 & 0.11 \\
\hline Energy intake (kcal/day) & $1748.72 \pm 952.40$ & $1609.35 \pm 715.23$ & 0.04 \\
\hline Fiber intake (g/day) & $19.81 \pm 20.78$ & $18.16 \pm 12.66$ & 0.48 \\
\hline Mg intake (mg/day) & $410.43 \pm 275.10$ & $374.56 \pm 197.48$ & 0.05 \\
\hline Ca intake(mg/day) & $560.81 \pm 551.12$ & $494.42 \pm 292.43$ & 0.18 \\
\hline Zn intake (mg/day) & $20.96 \pm 8.26$ & $19.71 \pm 6.40$ & 0.02 \\
\hline Fe intake (mg/day) & $33.60 \pm 29.27$ & $30.54 \pm 16.29$ & 0.07 \\
\hline Serum Mg (mmol/L) & $0.89 \pm 0.08$ & $0.92 \pm 0.07$ & 0.00 \\
\hline Serum TG (mmol/L) & $2.79 \pm 2.50$ & $1.88 \pm 17.71$ & 0.00 \\
\hline Serum LDL (mmol/L) & $2.89 \pm 1.00$ & $2.95 \pm 0.93$ & 0.49 \\
\hline Serum HDL (mmol/L) & $1.34 \pm 0.34$ & $1.54 \pm 0.38$ & 0.00 \\
\hline
\end{tabular}

Data are mean \pm standard deviation, unless otherwise indicated. $P$ values are for the test of difference between the diabetes population and non-diabetes population $B M I$ body mass index, Mg magnesium, Ca calcium, $Z n$ zinc, Fe iron, $T G$ triglyceride, HDL high-density lipoprotein cholesterol, LDL low-density lipoprotein cholesterol 
Table 2 Multivariable-adjusted relationship between magnesium intake and diabetes

\begin{tabular}{|c|c|c|c|c|c|}
\hline & \multicolumn{4}{|c|}{ Quartiles of Mg intake } & \multirow[t]{2}{*}{$P$ for trenc } \\
\hline & Q1 (lowest) & Q2 & Q3 & Q4 (highest) & \\
\hline Median Mg intake (mg/day) & 179.95 & 284.46 & 399.42 & 612.95 & - \\
\hline No. of subjects & 726 & 726 & 726 & 726 & - \\
\hline No. of cases & 68 & 69 & 62 & 95 & - \\
\hline aModel 1 & 1.00 (reference) & $0.85(0.59,1.23)$ & $0.71(0.48,1.05)$ & $1.00(0.66,1.51)$ & 0.82 \\
\hline Model 2 & 1.00 (reference) & $0.86(0.59,1.25)$ & $0.74(0.49,1.13)$ & $1.18(0.67,2.06)$ & 0.54 \\
\hline Model 3 & 1.00 (reference) & $0.86(0.59,1.26)$ & $0.77(0.50,1.19)$ & $1.18(0.66,2.13)$ & 0.54 \\
\hline
\end{tabular}

Data are adjusted OR $(95 \% \mathrm{Cl})$, unless otherwise indicated

${ }^{a}$ Model 1 included age, sex, BMI $\left(\geq 25,<25 \mathrm{~kg} / \mathrm{m}^{2}\right)$, and dietary energy intake of participants; model 2 added dietary fiber, calcium, zinc, and iron intake on the basis of model 1; model 3 added educational level, activity level, hypertension, alcohol and cigarette using condition, and nutritional supplementation on the basis of model 2

the three models also indicated an insignificant association between dietary $\mathrm{Mg}$ intake and diabetes $(P>0.05)$.

The concentration of serum $\mathrm{Mg}$ was $0.89 \pm$ $0.08 \mathrm{mmol} / \mathrm{L}$ in the diabetes population, which was significantly lower than that in the non-diabetes population $(0.92 \pm 0.07 \mathrm{mmol} / \mathrm{L}, \quad P<0.001)$. The results of the multivariable-adjusted association between serum $\mathrm{Mg}$ and diabetes are displayed in Table 3. According to the results of the multivariable logistic regression, there was a strong inverse correlation between serum $\mathrm{Mg}$ and diabetes. The multivariate adjusted ORs for diabetes were 0.38 (95\% CI 0.27, 0.54) in model 1, 0.34 (95\% CI 0.24, 0.50 ) in model 2 , and 0.34 (95\% CI 0.24, 0.49) in model 3 for the highest quartile of serum $\mathrm{Mg}$ compared with the lowest. The $P$ values for trend were less than 0.001 in all the three models.

The relationship between $\mathrm{Mg}$ intake and serum $\mathrm{Mg}$ was also tested by the Spearman correlation coefficient. The association between $\mathrm{Mg}$ intake and serum $\mathrm{Mg}$ was positively correlated in the total study population ( $r=$ $0.049, P=0.009)$. After stratification by diabetes, a significantly positive correlation was only found in the non-diabetes population $(r=0.060, P=0.006)$, but not in the diabetes population $(P=0.936)$.

\section{Discussion}

A cross-sectional study with a large sample size (2904 subjects) was conducted in the Hunan Province of China, aiming at exploring the relationship among dietary $\mathrm{Mg}$ intake, serum Mg, and diabetes in Chinese adults. According to our knowledge, this is the first report about the association among the three elements in the Chinese population. The prevalence of diabetes of the study population was $10.1 \%$, which was very close to the estimated level (11.6\%) investigated on a representative sample of Chinese adults in 2010 [32]. This could suggest a good representativeness of this study population. In this research, it was found that dietary Mg intake was not significantly correlated with diabetes, but serum $\mathrm{Mg}$ was in a strongly inverse correlation with diabetes. Meanwhile, there was not a significant association between dietary $\mathrm{Mg}$ intake and serum $\mathrm{Mg}$ in the diabetes population.

Most studies have suggested a significantly inverse correlation between dietary $\mathrm{Mg}$ and diabetes [9-16], but there were also some researchers concluding that the relationship between dietary $\mathrm{Mg}$ and diabetes was insignificant [17-23]. Such inconsistency was mainly found in Asia. Three studies [19, 21, 23], together with this research, indicated that dietary $\mathrm{Mg}$ was not significantly correlated with diabetes in Asian populations. Dietary

Table 3 Multivariable-adjusted relationship between serum magnesium and diabetes

\begin{tabular}{|c|c|c|c|c|c|}
\hline & \multicolumn{4}{|c|}{ Quartiles of serum Mg } & \multirow[t]{2}{*}{$P$ for trend } \\
\hline & Q1 (lowest) & Q2 & Q3 & Q4 (highest) & \\
\hline Median Mg concentration (mmol/L) & 0.84 & 0.90 & 0.94 & 1.00 & - \\
\hline No. of subjects & 827 & 672 & 710 & 695 & - \\
\hline No. of cases & 130 & 57 & 58 & 49 & - \\
\hline aModel 1 & 1.00 (reference) & $0.48(0.34,0.67)$ & $0.45(0.32,0.62)$ & $0.38(0.27,0.54)$ & 0.00 \\
\hline Model 2 & 1.00 (reference) & $0.48(0.34,0.68)$ & $0.45(0.32,0.63)$ & $0.34(0.24,0.50)$ & 0.00 \\
\hline Model 3 & 1.00 (reference) & $0.48(0.34,0.68)$ & $0.45(0.32,0.63)$ & $0.34(0.24,0.49)$ & 0.00 \\
\hline
\end{tabular}

Data are adjusted OR $(95 \% \mathrm{Cl})$, unless otherwise indicated

${ }^{a}$ Model 1 included age, sex, and BMI $\left(\geq 25,<25 \mathrm{~kg} / \mathrm{m}^{2}\right)$; model 2 added serum triglycerides, serum LDL, and serum HDL on the basis of model 1 ; model 3 added educational level, activity level, hypertension, alcohol and cigarette using condition, and nutritional supplementation on the basis of model 2 
$\mathrm{Mg}$ is closely associated with other healthy lifestyles and dietary factors, such as fiber and calcium intake [33], and therefore, it seems inappropriate to explain the effect of $\mathrm{Mg}$ intake based on its association with diabetes alone. Previous studies have built various multivariable models to predict the effects of $\mathrm{Mg}$ intake on the risk of diabetes; however, most outcomes were not adjusted by fiber or calcium intake [9-16]. Nanri et al. [19] suggested that the lean body composition of the Asian population might be one of the primary causes of the relatively less significant association between $\mathrm{Mg}$ and diabetes. Since Mg may affect insulin resistance, the Asian population probably has less insulin resistance compared to the Western population due to the leaner body composition. Meanwhile, the differences between this study and other studies targeting non-Asian populations may be attributed to the general dietary habits. In the Chinese diet, the major source of $\mathrm{Mg}$ is cereals, such as white rice; this is very different from Western dietary habits. The study population of this research might have a higher $\mathrm{Mg}$ intake from cereal products compared to the Western populations, which resulted in the inconsistent association between dietary $\mathrm{Mg}$ and diabetes.

The strong inverse association between serum $\mathrm{Mg}$ and diabetes observed in this study is consistent with the findings of several other epidemiological studies $[17,20$, 26, 34-36]. Previous studies have proved that a low level of $\mathrm{Mg}$ would damage insulin receptor function and decrease insulin sensitivity [37]. Serum $\mathrm{Mg}$ is always an important pointer of $\mathrm{Mg}$ deficiency, though extracellular $\mathrm{Mg}$ only accounts for $1 \%$ of the total body $\mathrm{Mg}$ [38]. On the opposite, diabetes could result in hypomagnesemia. The case-control study conducted by Lecube et al. [35] suggested that diabetes was the main factor accounting for the low concentration of serum Mg observed in morbidly obese subjects, because insulin deficiency or resistance could inhibit $\mathrm{Mg}$ re-absorption and accelerate its excretion in the kidney $[1,39]$. The urinary $\mathrm{Mg}$ was not measured in the present study. However, it was found that $\mathrm{Mg}$ intake was not significantly associated with diabetes. Since $\mathrm{Mg}$ homeostasis is mainly regulated by the balance between intestinal absorption and renal excretion $[38,39]$, a possible explanation for the low concentration of serum $\mathrm{Mg}$ in diabetes subjects could be the increased renal $\mathrm{Mg}$ excretion which was caused by insulin deficiency or resistance.

The present study also examined the association between dietary $\mathrm{Mg}$ and serum $\mathrm{Mg}$. We also found that the correlation between dietary $\mathrm{Mg}$ and serum $\mathrm{Mg}$ did not exist in diabetes subjects. Although there were significantly positive associations between dietary $\mathrm{Mg}$ and serum $\mathrm{Mg}$ in the total population and non-diabetes population, the correlation coefficients were extremely low ( $r=0.049$ and $r=0.060$, respectively). We could not be sure whether this statistical significance resulted from the large sample size or the actual association between dietary $\mathrm{Mg}$ and serum $\mathrm{Mg}$.

As a major strength, this is the first study that evaluated the relationship among dietary $\mathrm{Mg}$, serum $\mathrm{Mg}$, and diabetes with a large sample size of the Chinese population. According to the results, dietary $\mathrm{Mg}$ was not significantly associated with diabetes, but serum Mg was in a significantly inverse correlation with diabetes. In addition, the relationship between dietary $\mathrm{Mg}$ and serum $\mathrm{Mg}$ in the Chinese population was also tested for the first time, and it revealed that the association between dietary $\mathrm{Mg}$ and serum Mg was not significant in diabetes subjects. The effects of increased insulin resistance on $\mathrm{Mg}$ homeostasis in diabetic subjects might be a possible explanation for these findings.

There were also several limitations in the present research. Firstly, this cross-sectional study was unable to explain the causal relationship among dietary $\mathrm{Mg}$, serum $\mathrm{Mg}$, and diabetes, but based on the results, it could be speculated that $\mathrm{Mg}$ and diabetes might interact with each other. This hypothesis needs to be confirmed by further prospective studies. Secondly, the effects of $\mathrm{Mg}$ supplements on serum Mg or diabetes were not evaluated. According to previous studies [40,41], Mg supplements may affect the serum $\mathrm{Mg}$ and/or glucose metabolism. Thirdly, the urinary $\mathrm{Mg}$ level was not measured either, further studies should combine the factor of urinary Mg to confirm the hypothesis that insulin resistance was responsible for the low concentration of serum $\mathrm{Mg}$ in diabetes subjects.

\section{Conclusions}

In conclusion, the main finding of this study was that dietary $\mathrm{Mg}$ was not significantly correlated with diabetes, while serum $\mathrm{Mg}$ was in a strongly inverse correlation with diabetes in the Chinese population. Meanwhile, dietary $\mathrm{Mg}$ and serum $\mathrm{Mg}$ were not significantly correlated in the diabetes population. According to our findings, it could be speculated that the low concentration of serum $\mathrm{Mg}$ in diabetes subjects was mainly caused by the enhanced insulin resistance, which could increase $\mathrm{Mg}$ excretion in urine.

\section{Acknowledgements}

This work was supported by the Hunan Provincial Innovation Foundation for Postgraduate (CX2014B096) and the Fundamental Research Funds for the Central Universities of Central South University (2014zzts070).

Authors' contributions

JW designed the study, analyzed the data, and drafted the manuscript. CZ, $G L$, and TY conceived of the study, participated in the study design and coordination, and helped to draft the manuscript. QG, $\mathrm{XL}$, and $\mathrm{CZ}$ collected the data and helped in the analysis of the data. All authors read and approved the final manuscript. 


\section{Competing interests}

The authors declare that they have no competing interests.

\section{Author details}

'Department of Epidemiology and Health Statistics, Xiangya School of Public Health, Central South University, Changsha, Hunan Province 410008, China. ${ }^{2}$ Health Management Center, Xiangya Hospital, Central South University, Changsha, Hunan Province 410008 , China. ${ }^{3}$ Department of Orthopaedics, Xiangya Hospital, Central South University, Changsha, Hunan Province 410008, China.

Received: 1 July 2015 Accepted: 4 October 2016

Published online: 18 October 2016

\section{References}

1. Barbagallo M, Dominguez LJ. Magnesium metabolism in type 2 diabetes mellitus, metabolic syndrome and insulin resistance. Arch Biochem Biophys. 2007:458(1):40-7.

2. Floege J. Magnesium in CKD: more than a calcification inhibitor? J Nephrol. 2015;28(3):269-77.

3. Saris NE, Mervaala E, Karppanen H, Khawaja JA, Lewenstam A. Magnesium. An update on physiological, clinical and analytical aspects. Clin Chim Acta. 2000;294(1-2):1-26.

4. Delva P. Magnesium and coronary heart disease. Mol Aspects Med. 2003; 24(1-3):63-78.

5. He K, Liu K, Daviglus ML, Morris SJ, Loria CM, Van Horn L, et al. Magnesium intake and incidence of metabolic syndrome among young adults. Circulation. 2006:113(13):1675-82.

6. Maier JA. Low magnesium and atherosclerosis: an evidence-based link. Mol Aspects Med. 2003;24(1-3):137-46.

7. Schulze MB, Schulz M, Heidemann C, Schienkiewitz A, Hoffmann K, Boeing $H$. Fiber and magnesium intake and incidence of type 2 diabetes: a prospective study and meta-analysis. Arch Intern Med. 2007;167(9):956-65.

8. Touyz RM. Role of magnesium in the pathogenesis of hypertension. Mol Aspects Med. 2003;24(1-3):107-36.

9. Hata A, Doi Y, Ninomiya T, Mukai N, Hirakawa Y, Hata J, et al. Magnesium intake decreases Type 2 diabetes risk through the improvement of insulin resistance and inflammation: the Hisayama Study. Diabet Med. 2013;30(12): 1487-94.

10. Hruby A, Meigs JB, O'Donnell CJ, Jacques PF, McKeown NM. Higher magnesium intake reduces risk of impaired glucose and insulin metabolism and progression from prediabetes to diabetes in middle-aged Americans. Diabetes Care. 2014;37(2):419-27.

11. Kirii K, Iso H, Date C, Fukui M, Tamakoshi A. Magnesium intake and risk of self-reported type 2 diabetes among Japanese. J Am Coll Nutr. 2010;29(2): 99-106.

12. Lopez-Ridaura R, Willett WC, Rimm EB, Liu S, Stampfer MJ, Manson JE, et al. Magnesium intake and risk of type 2 diabetes in men and women. Diabetes Care. 2004;27(1):134-40.

13. Song Y, Manson JE, Buring JE, Liu S. Dietary magnesium intake in relation to plasma insulin levels and risk of type 2 diabetes in women. Diabetes Care. 2004;27(1):59-65.

14. van Dam RM, Hu FB, Rosenberg L, Krishnan S, Palmer JR. Dietary calcium and magnesium, major food sources, and risk of type 2 diabetes in U.S. black women. Diabetes Care. 2006;29(10):2238-43.

15. Villegas R, Gao YT, Dai Q, Yang G, Cai H, Li H, et al. Dietary calcium and magnesium intakes and the risk of type 2 diabetes: the Shanghai Women's Health Study. Am J Clin Nutr. 2009;89(4):1059-67.

16. Weng LC, Lee NJ, Yeh WT, Ho LT, Pan WH. Lower intake of magnesium and dietary fiber increases the incidence of type 2 diabetes in Taiwanese. J Formos Med Assoc. 2012;111(11):651-9.

17. Hopping BN, Erber E, Grandinetti A, Verheus M, Kolonel LN, Maskarinec G. Dietary fiber, magnesium, and glycemic load alter risk of type 2 diabetes in a multiethnic cohort in Hawaii. J Nutr. 2010;140(1):68-74

18. Kao WH, Folsom AR, Nieto FJ, Mo JP, Watson RL, Brancati FL. Serum and dietary magnesium and the risk for type 2 diabetes mellitus: the Atherosclerosis Risk in Communities Study. Arch Intern Med. 1999; 159(18):2151-9.

19. Nanri A, Mizoue T, Noda M, Takahashi Y, Kirii K, Inoue M, et al. Magnesium intake and type II diabetes in Japanese men and women: the Japan Public Health Center-based Prospective Study. Eur J Clin Nutr. 2010;64(10):1244-7.
20. Sales CH, Pedrosa LF, Lima JG, Lemos TM, Colli C. Influence of magnesium status and magnesium intake on the blood glucose control in patients with type 2 diabetes. Clin Nutr. 2011;30(3):359-64.

21. Shi ZM, Hu XS, Yuan BJ, Gibson R, Dai Y, Garg M. Association between magnesium: iron intake ratio and diabetes in Chinese adults in Jiangsu Province. Diabet Med. 2008;25(10):1164-70.

22. Walti MK, Zimmermann MB, Spinas GA, Jacob S, Hurrell RF. Dietary magnesium intake in type 2 diabetes. Eur J Clin Nutr. 2002;56(5):409-14.

23. Wang JL, Shaw NS, Yeh HY, Kao MD. Magnesium status and association with diabetes in the Taiwanese elderly. Asia Pac J Clin Nutr. 2005;14(3):263-9.

24. Liu ZM, Ho SC. The association of serum C-reactive protein, uric acid and magnesium with insulin resistance in Chinese postmenopausal women with prediabetes or early untreated diabetes. Maturitas. 2011;70(2):176-81.

25. Xu B, Sun J, Deng $X$, Huang $X$, Sun $W, X u$ Y, et al. Low serum magnesium level is associated with microalbuminuria in Chinese diabetic patients. Int J Endocrinol. 2013;2013:580685.

26. $\mathrm{Xu} J, \mathrm{Xu} \mathrm{W}$, Yao H, Sun W, Zhou Q, Cai L. Associations of serum and urinary magnesium with the pre-diabetes, diabetes and diabetic complications in the Chinese Northeast population. PLoS One. 2013;8(2), e56750.

27. Wei J, Lei GH, Fu L, Zeng C, Yang T, Peng SF. Association between dietary vitamin C intake and non-alcoholic fatty liver disease: a cross-sectional study among middle-aged and older adults. PLoS One. 2016;11(1), e147985.

28. Wei J, Zeng C, Gong QY, Li XX, Lei GH, Yang TB. Associations between dietary antioxidant intake and metabolic syndrome. PLoS One. 2015;10(6), e130876.

29. Wei J, Zeng C, Gong QY, Yang HB, Li XX, Lei GH, et al. The association between dietary selenium intake and diabetes: a cross-sectional study among middle-aged and older adults. Nutr J. 2015;14:18

30. Yang Y. Chinese food composition. Beijing: Peking University Medical Press; 2009.

31. Sun $\mathrm{CH}$. Nutrition and food hygiene. Beijing: People's Medical Publishing House; 2013.

32. Xu Y, Wang L, He J, Bi Y, Li M, Wang T, et al. Prevalence and control of diabetes in Chinese adults. JAMA. 2013;310(9):948-59.

33. Dong JY, Xun P, He K, Qin LQ. Magnesium intake and risk of type 2 diabetes: meta-analysis of prospective cohort studies. Diabetes Care. 2011; 34(9):2116-22.

34. Chambers EC, Heshka S, Gallagher D, Wang J, Pi-Sunyer FX, Pierson RJ. Serum magnesium and type-2 diabetes in African Americans and Hispanics: a New York cohort. J Am Coll Nutr. 2006;25(6):509-13.

35. Lecube A, Baena-Fustegueras JA, Fort JM, Pelegri D, Hernandez C, Simo R. Diabetes is the main factor accounting for hypomagnesemia in obese subjects. PLoS One. 2012;7(1), e30599.

36. Yang SJ, Hwang SY, Baik SH, Lee KW, Nam MS, Park YS, et al. Serum magnesium level is associated with type 2 diabetes in women with a history of gestational diabetes mellitus: the Korea National Diabetes Program study. J Korean Med Sci. 2014;29(1):84-9.

37. Barbagallo M, Dominguez $\sqcup$, Galioto A, Ferlisi A, Cani C, Malfa L, et al. Role of magnesium in insulin action, diabetes and cardio-metabolic syndrome $X$. Mol Aspects Med. 2003:24(1-3):39-52.

38. Ayuk J, Gittoes NJ. Contemporary view of the clinical relevance of magnesium homeostasis. Ann Clin Biochem. 2014;51(Pt 2):179-88.

39. Sales CH, Pedrosa LF. Magnesium and diabetes mellitus: their relation. Clin Nutr. 2006;25(4):554-62.

40. Balon TW, Jasman A, Scott S, Meehan WP, Rude RK, Nadler JL. Dietary magnesium prevents fructose-induced insulin insensitivity in rats. Hypertension. 1994;23(6 Pt 2):1036-9.

41. Song Y, He K, Levitan EB, Manson JE, Liu S. Effects of oral magnesium supplementation on glycaemic control in Type 2 diabetes: a meta-analysis of randomized double-blind controlled trials. Diabet Med. 2006;23(10):1050-6. 